\title{
Generic Competences for the IT Knowledge Workers: A Study from the Field
}

\author{
Ricardo Colomo-Palacios ${ }^{1}$, Fernando Cabezas-Isla ${ }^{1}$, \\ Ángel García-Crespo ${ }^{1}$, and Pedro Soto-Acosta ${ }^{2}$ \\ ${ }^{1}$ Universidad Carlos III de Madrid, Computer Science Department \\ Av. Universidad 30, Leganés, 28911, Madrid, Spain \\ \{ricardo.colomo, fernando.cabezas, angel.garcia\}@uc3m.es \\ ${ }^{2}$ University of Murcia, Department of Management \& Finance, \\ Campus de Espinardo, 30100 Murcia, Spain \\ psotodum.es
}

\begin{abstract}
This paper aims to identify generic competency levels relevant to a particular kind of knowledge workers: software engineers. Based on previous works, and in particular in the description of a professional career, authors review of the literature related to the characterization of the labor force in the Software Engineering (SE) domain. Subsequently, using a quantitative analysis based on investigative surveys administered to a number of representative professionals, authors provide with a generic competency ladder adapted to the given career description.
\end{abstract}

Keywords: Competences, Competency Levels, Software Engineering, Career.

\section{Introduction}

The development of intellectual capital of corporations represents one of the most significant challenges for today's managers, and one of the most fertile fields for business innovation, human resource management and education research [1]. In Information Technology (IT), a knowledge intensive activity in which organizations support their activities [2], the importance of people is unquestionable. Within IT, software development is an intense human capital activity, more based in intellectual capital [3]. But, in spite of its importance, some authors (e.g. [4]) have indicated that the influence of competencies on the success of projects has not been successfully explored. Such competencies, key factor for project success, in the case of IT workers must be continually revised and improved in order to adapt workers competences' to technical innovations and soft skills to evolving markets [5].

Based on the professional career stated in [6], in which it was established from seven consecutive profiles (a pyramidal model), in this paper, via an empirical research, is established the generic competency levels for every role in that professional ladder.

The remainder of the paper is organized as follows. Section 2 outlines relevant literature in the area about the field of study. In Section 3, the study conducted is 
presented along with the description of the sample and the methods used. Conclusions and future work are discussed in Section 4.

\section{Competency: The Technical and the Generic}

Competences can be defined as an individual's core skills that are causally related to a specific, effective criterion and/or a superior performance at work [7]. Early 20th century scientific management used the concept of competence [8], and is well established in the field of human resources management since the middle of the seventies, due to the works by McClelland [9]. The concept of competence is associated with the analysis of professional activities and the inventory of what is necessary in order to accomplish the missions involved in these activities [10]. In [10] a taxonomy of competence is set. In this taxonomy particular or technical competences are established as those that are necessary to carry out a very specific task of a particular job position and include knowledge, abilities, and skills. On the other hand, universal or generic competences are those that, though not linked to a specific activity or function, do make possible the competent performance of the tasks related to the work position, inasmuch as they refer to characteristics or abilities of the individual's general behaviour. These competences permit individuals to adapt to changes in a more efficient and rapid way [10]. Generic competences and may be crucial for IT project success [11] but also for a wider range of organizational contexts, including all knowledge workers [12].

Due to its importance many studies have been devoted to work out which competences are crucial for IT people, some of them devoted to specific profiles (e.g. [13], [14), while others are more general (e.g. [15], [16]). A few studies are devoted specifically to set generic competences (e.g. [1], [17]), while others take advantage of ongoing education normalization processes (e.g. [18], [19]) and set both technical and generic competences. In this study, taking advantages of the career ladder defined in [6] and using the generic competences defined in [19], for each professional profile defined it is set a level of generic competency by means of the application of a questionnaire to a selected group of IT professionals.

\section{The Study: Putting Generic Competencies into a Software Engineering Career Structure}

Competency studies for software engineers do not show competency levels, and focus only on the possession of competencies evident in professionals which are relevant for successful job fulfillment. Given this current status, it was regarded fundamental to perform a study which analyses the opinions of professionals active in the IT field today [6].

To do so, in the first term, there's a need to describe software engineering career ladder described in [6] in which 7 consecutive steps from $G$ (lower \& entry level) to A (higher level) is defined. It is also needed to specify the set of generic competences used for the study. Table 1 displays a list of generic competence for computer science according to Casanovas et al. [19]. 
Table 1. Set of generic competences for computer science according to [19]

\begin{tabular}{lr}
\hline Competence & $\#$ \\
\hline Capacity for analysis and synthesis & 1 \\
Organization and planning & 2 \\
Oral and written communication in mother tongue & 3 \\
Problem solving & 4 \\
Decision-making & 5 \\
Critical thinking & 6 \\
Team work & 7 \\
Interpersonal skills & 8 \\
Ability to work on an interdisciplinary team & 9 \\
Information management & 10 \\
Ability to work in an international context & 11 \\
Ethical commitment & 12 \\
Environmental sensibility & 13 \\
Adaptation/flexibility & 14 \\
Creativity & 15 \\
Leadership & 16 \\
Understanding of other cultures and customs & 17 \\
Ability to work in an autonomous way & 18 \\
Initiative and enterprise & 19 \\
Quality concern & 20 \\
\hline
\end{tabular}

\subsection{Research Design}

The study consists of the application of a questionnaire in order to define competencies for the SE professional profiles. A Likert scale with an even number of values was used, ranging from 1 to 4 points. The description of the scale will be generic for all competencies, showing the following order of values and descriptions:

1= Low Level; 2= Medium Level; 3= High Level; 4= Very High Level

Once final formats were edited, subjects received their questionnaires through email and sent their responses using this mean in a given period of time.

\subsection{Sample Description}

The sample consists of 47 professionals working in software development jobs within large enterprises (over 500 employees) during a period of, at least, five years. The distribution of the subjects within the categories identified previously was subsequently established, based on the interviews: 21 " $\mathrm{D}$ " (42\%), 20 "CC" (40\%), 5 "D" $(10 \%)$ and 4 "A" $(8 \%)$. The distribution of experimental subjects shows that it was comprised of 6 women $(13 \%)$ and 41 men (87\%). The average age was 36.2, with an average experience in the business of 10.52 years.

\subsection{Results and Discussion}

With the objective of determining the scores obtained for each element, an average and standard deviation was calculated for the results obtained in relation to the 
Table 2. Results of the study (Average and Standard Deviation)

\begin{tabular}{|c|c|c|c|c|c|c|c|c|c|c|c|c|c|c|}
\hline Com\# & $\mathrm{G}$ & & $\mathrm{F}$ & & E & & D & & C & & B & & A & \\
\hline & $\mathrm{A}$ & St & A & $\mathrm{St}$ & $\mathrm{A}$ & St & $\mathrm{A}$ & St & $\mathrm{A}$ & St & A & St & $\mathrm{A}$ & \\
\hline 1 & 1.66 & 0.90 & 2.34 & 0.80 & 3.26 & 0.63 & 3.84 & 0.37 & 3.74 & 0.43 & 3.34 & 0.75 & 3.12 & 1.00 \\
\hline 2 & 1.58 & .76 & 2.08 & .83 & 2.78 & 76 & & 0.61 & .00 & 00 & .90 & 36 & .76 & 0.52 \\
\hline 3 & 2.02 & 1.02 & 2.28 & 0.93 & 2.88 & 0.77 & 3.22 & 0.71 & 3.64 & 0.60 & 3.86 & 0.54 & 3.78 & 0.71 \\
\hline 4 & .06 & 0.91 & 2.64 & 0.90 & 3.18 & 0.83 & 3.58 & 0.61 & 3.62 & 0.53 & 3.46 & 0.76 & 3.42 & 0.86 \\
\hline 5 & 1.26 & 0.60 & 1.68 & 0.74 & 2.48 & 0.68 & 2.98 & 0.69 & 3.74 & 0.44 & 3.90 & 0.30 & 3.94 & 0.31 \\
\hline & 10 & 0.95 & 2.48 & 0.89 & 3.04 & 0.81 & 3.48 & 0.71 & 3.62 & 0.64 & 3.50 & 0.68 & 3.44 & 0.86 \\
\hline & 18 & .90 & 3.46 & 0.71 & 3.72 & 0.54 & 3.80 & 0.45 & 3.78 & 0.47 & 3.12 & 0.77 & 2.76 & 1.10 \\
\hline & & 87 & .08 & 0.83 & 2.46 & & & 0.77 & 3.68 & 0.47 & 3.76 & 0.48 & 3.78 & 0.51 \\
\hline & 32 & .02 & 2.64 & 0.96 & 3.14 & 0.81 & 3. & 0.68 & 3.70 & 0.58 & 3.40 & 0.73 & 3.14 & 0.97 \\
\hline 0 & .64 & 0.66 & 2.12 & 0.77 & 2.94 & 0.77 & 3.48 & 0.58 & 3.74 & 0.49 & 3.70 & 0.54 & 3.60 & 0.73 \\
\hline 11 & 1.48 & 0.73 & 1.80 & 0.76 & 2.18 & 0.75 & 2.64 & 0.75 & 3.18 & 0.72 & 3.56 & 0.71 & 3.70 & 0.68 \\
\hline 12 & 2.62 & 1.09 & 2.78 & 0.95 & 3.04 & 0.83 & 3.30 & 0.79 & 3.60 & 0.67 & 3.66 & 0.59 & 3.58 & 0.76 \\
\hline & 88 & 0.96 & 1.96 & 0.95 & 2.06 & 0.94 & 2.16 & 0.98 & 2.34 & 1.00 & 2.34 & 1.03 & 2.86 & 1.13 \\
\hline 4 & & 1.07 & 2.78 & 1.00 & 3.18 & 0.75 & 3.44 & 0.58 & 2.64 & 0.56 & 3.46 & 0.79 & 3.40 & 0.81 \\
\hline 5 & & 0.9 & 2.72 & 0.93 & 3.28 & 0.7 & 3.58 & 0.61 & 3.32 & 0.77 & 3.00 & 0.93 & 2.88 & 1.06 \\
\hline 6 & & & .62 & 0.67 & 2.32 & & 3.02 & 0.69 & 3.70 & 0.46 & 3.78 & 0.42 & 3.90 & 0.36 \\
\hline 17 & 1.56 & 81 & 1.76 & 0.87 & 1.92 & 0.8 & 2.18 & 0.77 & 2.64 & 0.90 & 2.96 & 0.94 & 2.82 & 0.90 \\
\hline 18 & 3.08 & .94 & 3.30 & 0.79 & 3.46 & 0.68 & 3.36 & 0.72 & 3.16 & 0.87 & 2.98 & 0.94 & 2.82 & 1.08 \\
\hline 19 & 2.08 & 0.99 & 2.46 & 0.89 & 2.72 & 0.81 & 3.04 & 0.73 & 3.38 & 0.60 & 3.40 & 0.65 & 3.60 & 0.68 \\
\hline 20 & 2.90 & 1.00 & 3.30 & 0.79 & 3.54 & 0.61 & 3.82 & 0.39 & 3.86 & 0.41 & 3.58 & 0.54 & 3.46 & 0.76 \\
\hline
\end{tabular}

relative importance of the scores. The results are demonstrated in Table $2(\mathrm{~A}=$ Average; $\mathrm{St}=$ Standard Deviation).

Standard deviations are, in general, less than unity. The cases of significant variability, for a total of thirteen, are presented on five occasions to the figures of " $\mathrm{A}$ " and "G", demonstrating once to the figures of "B", "C" and "F". With regards to competences, two roles present standard deviations greater than unity for "Environmental sensibility".

The most important competence for all professional figures, according to the sum of their averages is "Quality concern" followed by "Team Work". The competence less valuable is "Environmental sensibility" followed by "Understanding of other cultures and customs". With respect to professional figures, the one that requires more generic competency, according to respondents is " $\mathrm{C}$ " followed by "B" and "A".

\subsection{Competency Level Proposal}

Table 3 shows the competency level required for generic competence and SE professional profile. Competency values have been attributed according to the scores given by the experimental subjects, reflecting competency requirements for different professional profiles. Scores, expressed in a Likert scale ranging from 1 to 4 , have initially been assigned by rounding the average scores for different professional profiles. Subsequently, they have been refined according to the competency scales which had been defined previously, in order to finally establish the evolution of competencies of 
employees in the business environment defined. This proposal however is different in a sense from sample opinions. According to them, the top level of generic competency levels is reached in " $C$ ". Our proposal is to reach this rank \#1 in A. This is due the conviction that, opposite from technical competence as stated in [6], generic competence improves with the time.

Table 3. Generic competence level per profile

\begin{tabular}{lccccccc}
\hline Competence & A & B & C & D & E & F & G \\
\hline Capacity for analysis and synthesis & 4 & 4 & 4 & 4 & 3 & 2 & 2 \\
Organization and planning & 4 & 4 & 4 & 3 & 3 & 2 & 2 \\
Oral and written communication in & 4 & 4 & 4 & 3 & 3 & 2 & 2 \\
mother tongue & & & & & & & \\
Problem solving & 4 & 4 & 4 & 4 & 3 & 3 & 2 \\
Decision-making & 4 & 4 & 4 & 3 & 2 & 2 & 1 \\
Critical thinking & 4 & 4 & 4 & 4 & 3 & 3 & 2 \\
Team work & 4 & 4 & 4 & 4 & 4 & 3 & 3 \\
Interpersonal skills & 4 & 4 & 4 & 3 & 2 & 2 & 2 \\
Ability to work on an & 4 & 4 & 4 & 3 & 3 & 3 & 2 \\
interdisciplinary team & & & & & & & \\
Information management & 4 & 4 & 4 & 4 & 3 & 2 & 2 \\
Ability to work in an international & 4 & 4 & 3 & 3 & 2 & 2 & 1 \\
context & & & & & & & \\
Ethical commitment & 4 & 4 & 4 & 3 & 3 & 3 & 3 \\
Environmental sensibility & 4 & 3 & 2 & 2 & 2 & 2 & 2 \\
Adaptation/flexibility & 4 & 4 & 4 & 4 & 3 & 3 & 2 \\
Creativity & 4 & 4 & 3 & 4 & 3 & 3 & 2 \\
Leadership & 4 & 4 & 4 & 3 & 2 & 2 & 1 \\
Understanding of other cultures and & 4 & 4 & 3 & 2 & 2 & 2 & 1 \\
customs & & & & & & & \\
Ability to work in an autonomous & 3 & 3 & 3 & 3 & 3 & 3 & 3 \\
way & & & & & & & \\
Initiative and enterprise & 4 & 4 & 3 & 3 & 3 & 2 & 2 \\
Quality concern & 4 & 4 & 4 & 4 & 4 & 3 & 3 \\
\hline
\end{tabular}

\section{Conclusions and Future Work}

People are a critical information technology (IT) issue [20]. Competences and competence structures for IT professionals can be seen as enablers for the Knowledge Society, needed also of intellectual capital and competent IT workers [21], moreover. Individual differences have been identified as one of the paradigms for the research of human factors in software development [22]. Those differences can be measured using the competence paradigm. However, in order to know the performance of a given worker, competency levels for each of the roles must be defined.

This paper aims at the identification of those levels using two known tools. On the one hand, the pyramidal model for professional careers, identifying one single professional track going from Junior Programmer to IT Director, identified in [6]. On the other hand, generic competences list provided by [19]. The result of the study 
conducted states generic competence levels for the ladder. According to its results, generic competence excellence is reached in a determined professional profile, in this case "C", followed by "B" and "A". The reason why "C" and not "A" is the top of the competence ranking can be found in that generic competences list provided by [19] is designed to be applied in a computer science academic context, without including management related competences. About most valued generic competences, "Quality concern" and "Team Work" can be seen as the most valued competences for software engineering professionals.

As future research, we propose to investigate the inclusion of more manager-like competences that can draw in a more accurate way higher roles. Moreover, authors suggest the creation of an evaluation model allowing the identification of strengths and weaknesses of the competencies of their employees using state of the art tools and technologies.

\section{Referentes}

1. Casado-Lumbreras, C., García-Crespo, Á., Colomo-Palacios, R., Gómez-Berbís, J.M.: Emotions and Interpersonal Skills for IT Professionals: an Exploratory Study. International Journal of Technology Enhanced Learning (2010) (in press )

2. Trigo, A., Varajao, J., Barroso, J.: A practitioner's roadmap to learning the available tools for Information System Function management. International Journal of Teaching and Case Studies 2(1), 29-40 (2009)

3. Sommerville, I., Rodden, T.: Human social and organizational influences on the software process. In: Fuggetta, A., Wolf, A. (eds.) Software Process (Trends in Software, 4), pp. 89-110. John Wiley \& Sons, New York (1996)

4. Turner, J.R., Müller, R.: The Project Manager's Leadership Style as a Success Factor on Projects: A Literature Review. Project Management Journal 36(2), 49-61 (2005)

5. Casado-Lumbreras, C., Colomo-Palacios, R., Gómez-Berbís, J.M., García-Crespo, Á.: Mentoring programmes: a study of the Spanish software industry. International Journal of Learning and Intellectual Capital 6(3), 293-302 (2009)

6. Colomo-Palacios, R., Tovar-Caro, E., García-Crespo, A., Gómez-Berbis, M.J.: Identifying Technical Competences of IT Professionals. The Case of Software Engineers. International Journal of Human Capital and Information Technology Professionals 1(1), 31-43 (2010)

7. Spencer, L.M., Spencer, S.M.: Competence at Work. Models for Superior Performance. Willey and sons, New York (1993)

8. Taylor, F.W.: The Principles of Scientific Management. Harper \& Brothers, New York (1911)

9. McClelland, D.C.: Testing for competence rather than for 'intelligence'. American Psychologist 28, 1-14 (1973)

10. Levy-Leboyer, C.: La gestion des compétences [Competence management]. Les Editions d'Organisation, Paris (1996)

11. Sukhoo, A., Barnard, A., Eloff, M.M., Van der Poll, J.A., Motah, M.: Accommodating Soft Skills in Software Project Management. Issues in Informing Science and Information Technology 2, 691-704 (2005)

12. Rimbau-Gilabert, E., Miyar-Cruz, D., López-de Pedro, J.M.: Breaking the boundary between personal- and work-life skills: parenting as a valuable experience for knowledge workers. International Journal of Knowledge and Learning 5(1), 1-13 (2009) 
13. McMurtrey, M.E., Downey, J.P., Zeltmann, S.M., Friedman, W.H.: Critical skill sets of entry level IT professionals: An empirical examination of perceptions from field personnel. Journal of Information Technology Education 7, 101-120 (2008)

14. Ruano-Mayoral, M., Colomo-Palacios, R., García-Crespo, A., Gómez-Berbís, J.M.: Software Project Managers under the Team Software Process. A Study of Competences Based on Literature. International Journal of Information Technology Project Management 1(1), 42-53 (2010)

15. Trigo, A., Varajão, J., Soto-Acosta, P., Barroso, J., Molina-Castillo, F.J., GonzalvezGallego, N.: IT Professionals: An Iberian Snapshot. International Journal of Human Capital and Information Technology Professionals 1(1), 61-75 (2010)

16. Kovacs, P.J., Caputo, D., Turchek, J., Davis, G.A.: A survey to define the skill sets of selected information technology professionals. Issues in Information Systems Journal 7(1), 242-246 (2006)

17. García-Crespo, A., Colomo-Palacios, R., Gómez-Berbís, J.M., Tovar-Caro, E.: IT Professionals' Competences: High School Students' Views. Journal of Information Technology Education 8(1), 45-57 (2009)

18. González, J., Wagenaar, R.: Tuning educational structures in Europe. Final report - Pilot project phase. University of Groningen and University of Deusto, Groningen and Bilbao (2003)

19. Casanovas, J., Colom, J.M., Morlán, I., Pont, A., Ribera, M.: Libro Blanco sobre las titulaciones universitarias en Informática en España [White Book: University degrees in computer engineering]. ANECA (2004)

20. Casado-Lumbreras, C., García-Crespo, A., Colomo-Palacios, R., Gómez-Berbís, J.M.: Emotions and interpersonal skills for IT professionals: an exploratory study. International Journal of Technology Enhanced Learning 2(3), 215-226 (2010)

21. Hernández-López, A., Colomo-Palacios, R., García-Crespo, A., Soto-Acosta, P.: Trust Building Process for Global Software Development Teams. A review from the Literature. International Journal of Knowledge Society Research 1(1), 66-83 (2010)

22. Curtis, B., Hefley, W.E., Miller, S.A.: People Capability Maturity Model (P-CMM®) Version 2.0. CMU/SEI-2001-MM-01 (2001) 